\title{
Effect of oral anticoagulants on the outcome of faecal immunochemical test
}

L Bujanda*,1 ${ }^{*}$ C Sarasqueta ${ }^{2}$, Á Lanas ${ }^{3}$, E Quintero ${ }^{4}$, J Cubiella ${ }^{5}$, V Hernandez ${ }^{6}$, J D Morillas ${ }^{7}$, T Perez-Fernández ${ }^{8}$, D Salas ${ }^{9}, \mathrm{M}$ Andreu ${ }^{10}, \mathrm{~F} \mathrm{Carballo}^{11}, \mathrm{X}$ Bessa $^{10}$, I Portillo ${ }^{12}, \mathrm{R}$ Jover $^{13}, \mathrm{~F} \mathrm{Balaguer}^{14}$, A Cosme ${ }^{1}$ and A Castells ${ }^{14}$ on behalf of COLONPREV study investigators ${ }^{15}$

${ }^{1}$ Department of Gastroenterology, Hospital Universitario Donostia, Instituto Biodonostia, Centro de Investigación Biomédica en Red en Enfermedades Hepáticas y Digestivas (CIBERehd), Universidad del País Vasco (UPV/EHU), San Sebastián, Spain; ${ }^{2}$ Hospital Universitario Donostia, Instituto Biodonostia, Red de Investigación en Servicios de Salud en Enfermedades Crónicas (REDISSEC), San Sebastián, Spain; ${ }^{3}$ Department of Gastroenterology, University of Zaragoza, IIS Aragón, CIBERehd, Zaragoza, Spain; ${ }^{4}$ Department of Gastroenterology, Hospital Universitario de Canarias, Universidad de La Laguna, Tenerife, Spain; ${ }^{5}$ Department of Gastroenterology, Complexo Hospitalario Universitario de Ourense, Ourense, Spain; ${ }^{6}$ Servicio de Aparato Digestivo, Complexo Hospitalario Universitario de Vigo, Vigo, Spain; ${ }^{7}$ Department of Gastroenterology, Hospital Clínico San Carlos, Madrid, Spain; ${ }^{8}$ Department of Gastroenterology, Hospital Fundación Alcorcón, Madrid, Spain; ${ }^{9}$ Programa de Cribado de Cáncer Colorrectal, Dirección General de Salud Pública, Conselleria de Sanitat, Valencia, Spain; ${ }^{10}$ Department of Gastroenterology, Hospital del Mar, IMIM, Barcelona, Catalonia, Spain; ${ }^{11}$ Unidad de Gestión Clínica de Digestivo, Hospital Universitario Virgen de la Arrixaca, Murcia, Spain; ${ }^{12}$ Centro Coordinador del Programa de Cribado Cáncer Colorrectal, Organización Central de Osakidetza-Servicio Vasco de Salud, Bilbao, Spain; ${ }^{13}$ Department of Gastroenterology, Hospital General Universitario de Alicante, Alicante, Spain and ${ }^{14}$ Department of Gastroenterology, Hospital Clínic, Centro de Investigación Biomédica en Red en Enfermedades Hepáticas y Digestivas (CIBERehd), IDIBAPS, University of Barcelona, Barcelona, Catalonia, Spain

Background: We aimed to evaluate whether oral anticoagulants (OACs) alter faecal immunochemical test (FIT) performance in average-risk colorectal cancer (CRC) screening.

Methods: Individuals aged 50-69 years were invited to receive one FIT sample (cutoff $75 \mathrm{ng} \mathrm{ml}^{-1}$ ) between November 2008 and June 2011.

Results: Faecal immunochemical test was positive in 9.3\% (21 out of 224) of users of OAC and $6.2 \%$ (365 out of 5821 ) of non-users $(P$-trend $=0.07)$. The positive predictive value (PPV) for advanced neoplasia (AN) in non-users was $50.4 \%$ vs $47.6 \%$ in users (odds ratio, $0.70 ; 95 \% \mathrm{Cl}, 0.3-1.8 ; P=0.5$ ). The PPV for AN in OAC more antiplatelets (aspirin or clopidogrel) was $75 \%$ (odds ratio, 2; 95\% $\mathrm{Cl}, 0.4-10.8 ; P=0.4$ ).

Conclusions: Oral anticoagulant did not significantly modify the PPV for AN in this population-based colorectal screening program. The detection rate of advanced adenoma was higher in the combination OAC more antiplatelets.

The faecal immunochemical test (FIT) is one of the tests recommended by different societies for colorectal cancer (CRC) screening in average-risk populations (Levin et al, 2008). Faecal immunochemical test is performed annually or biennially after age 50. In a recently published population-based, randomised trial,
FIT detected an equivalent number of CRC as colonoscopy in the first CRC screening round (Quintero et al, 2012).

There is no consensus among experts about whether oral anticoagulants (OACs) alone or in combination with antiplatelet drugs should be suspended before stool collection for FIT

*Correspondence: Dr L Bujanda; E-mail: medik@telefonica.net

${ }^{15} \mathrm{All}$ investigators are listed in the Supplementary note.

Received 17 September 2013; revised 20 December 2013; accepted 8 January 2014; published online 4 February 2014 (c) 2014 Cancer Research UK. All rights reserved 0007-0920/14 
(Levi et al, 2009; Sawhney et al, 2010; Mandelli et al, 2011). Previous studies from our group have observed aspirin and antiplatelets should not be stopped before FIT, as these drugs do not diminish the positive predictive value (PPV) for advanced neoplasia (AN; Bujanda et al, 2013).

The objective of this study was to determine whether the use of $\mathrm{OAC}$, alone or in combination with antiplatelet drugs, affects the positivity and detection rates for $\mathrm{AN}$ in average-risk subjects undergoing CRC screening.

\section{MATERIALS AND METHODS}

Study design. We performed a post hoc analysis of subjects assigned to the FIT arm of the COLONPREV trial, a randomised controlled study aimed at comparing one-time colonoscopy vs biennial FIT for the reduction of CRC-related mortality at 10 years in an average-risk population. The study, described in detail elsewhere (Quintero et al, 2012), started in November 2008 and the first round was completed in June 2011. Subjects agreeing to participate in the study received an appointment to the local screening office. The data manager conducted a questionnaire (face to face) about taking drugs (type, dose and frequency). Patients usually have a list of the drugs they take. At the time of the interview, data manager explained how to make the FIT without stopping any medication.

Faecal immunochemical test strategy consisted of a single sample using the automated semiquantitative OC-Sensor kit (Eiken Chemical Co., Tokyo, Japan), without any specific diet or medication limitations. Patients with $\geqslant 75 \mathrm{ng}$ haemoglobin per $\mathrm{ml}$ of buffer solution ( $\geqslant 15 \mu \mathrm{g}$ of haemoglobin per gram of faeces) were invited for a colonoscopy (Fraser et al, 2012).

Within this cohort, we defined the 'users' as those reporting chronic use of OAC (acenocoumarol), alone or in combination with antiplatelet drugs. Antiplatelet drugs were aspirin $\leqslant 300 \mathrm{mg}$ $\mathrm{day}^{-1}$ or clopidogrel. The non-users group consisted of subjects not taking any of these drugs, either chronically or sporadically, within 30 days of testing. Patients taking these drugs intermittently or sporadically within 30 days of testing were excluded from the analysis. Individuals taking new anticoagulants (dabigatran, rivaroxaban, apixaban and edoxaban) or non-steroidal antiinflammatory drugs were also excluded. No change in medication before stool collection was recommended.

Adenomas $\geqslant 10 \mathrm{~mm}$ in size, with villous architecture, high-grade dysplasia or intramucosal carcinoma were classified as advanced adenomas. Advanced neoplasia was defined as advanced adenoma or invasive cancer. Non-AN (NAN) were classified as the presence of one or two small adenomas $<10 \mathrm{~mm}$. Invasive cancer was considered to exist when malignant cells were observed beyond the muscularis mucosa. A specific program was designed to ensure the quality of the whole process (Jover et al, 2012; Quintero et al, 2012).

Statistical analysis. Chi-square test and/or Fisher test was used to compare categorical variables across the groups and one-way ANOVA was used to compare continuous variables. Faecal haemoglobin measurements are presented as medians and compared using the non-parametric Kruskal-Wallis test. The positivity rate and the PPV was calculated for the users and nonusers group.

\section{RESULTS}

Postal invitations to undergo FIT were sent to a total of 28696 individuals, with a mean age of $59.5 \pm 5.5$ years, $47 \%$ were men. Of them 1054 (3.6\%) invitations were returned unanswered.
In addition, $1043(3.6 \%)$ were excluded either permanently or temporarily. The eligible population consisted of 26599 people.

A total of 10611 (36.9\%) individuals returned the test and 6045 (56.9\%) fulfilled the questionnaire and reported adequate information on the use of OAC (Figure 1). Mean age was $59.5 \pm 5.6$ years and 2803 (46\%) were men. Of the 6045 participants, 5821 (96.3\%) reported not using any of these drugs (non-users group), and 224 (3.7\%) reported taking OAC alone or in combination with antiplatelet drugs before testing (users group). In the users group, 164 individuals reported taking OAC alone and 60 OAC in combination with antiplatelet drugs. As expected, more men were taking these drugs than women and age was higher in those taking antiplatelet drugs than in non-users (Table 1). There were no differences in the type or the location of lesions (CRC, AN and NAN) between users and non-users group.

Faecal immunochemical test was positive for occult blood in 386 of 6045 participants $(6.3 \%)$. Of the 386 people with positive test, colonoscopy was normal in $124(32 \%)$ cases, whereas $20(5 \%)$ had CRC, $174(45 \%)$ AA and $68(18 \%)$ NAN. Tumour staging of identified lesions (FIT: stage I in 16; stage II in 2 and stage III in 2).

Faecal immunochemical test was positive in (21 out of 224) $9.3 \%$ of the users group and (365 out of 5821) $6.2 \%$ in the nonusers group $(P$-trend $=0.07$; Table 2$)$. The number of $\mathrm{AN}$ found in the OAC more antiplatelet therapy users not differ significantly with non-users (Table 3). The PPV for AN in OAC more antiplatelets (aspirin or clopidogrel) was $75 \%$ (odds ratio, 2; 95\% CI, $0.4-10.8 ; P=0.4$ ). Median haemoglobin concentration detected in the stool did not differ significantly between non-users and users (285 $\mathrm{ng} \mathrm{ml}^{-1}$ vs $502 \mathrm{ng} \mathrm{ml}^{-1}$; $P$-trend $=0.2$ ).

The PPV for AN in the non-user group was $50.4 \%$ and $47.6 \%$ (Table 4). The PPV for NAN was $50.4 \%$ (184 out of 365 ), $30.8 \%$ (4 out of 13) and 75\% (6 out of 8), in the non-users, OAC, and $\mathrm{OAC}$ in combination with other drugs respectively, without significant differences $(P=0.2)$.

\section{DISCUSSION}

The number of people with long-term OAC therapy is increasing. In $2006,4 \%$ of the population taking OAC (equal to our study) and 9\% of those over 65 years (Dossett et al, 2011). Patients with prosthetic heart valves, chronic or paroxysmal atrial fibrillation, recurrent deep venous thrombosis, hypercoagulable diseases, and vascular diseases are currently maintained on long-term anticoagulants. Anticoagulation is mandatory to reduce the risk of

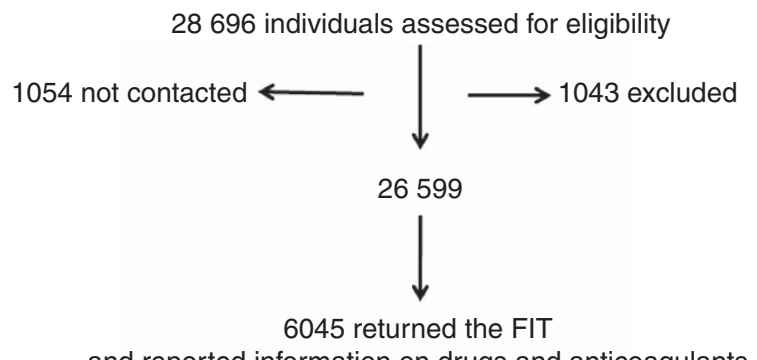

and reported information on drugs and anticoagulants

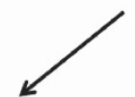

5821 nonusers group

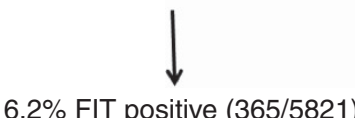

ve $(365 / 5821)$

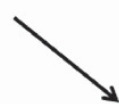

224 users group

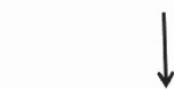

9.3\% FIT positive (21/224)
Figure 1. Study recruitment and participant flow. 


\begin{tabular}{|c|c|c|c|}
\hline & $\begin{array}{c}\text { Users } \\
\text { group } \\
(n=224)\end{array}$ & $\begin{array}{c}\text { Non-users } \\
\text { group } \\
(n=5821)\end{array}$ & $P$-value \\
\hline Positive FIT & $21(9.3 \%)$ & $365(6.2 \%)$ & 0.07 \\
\hline Age (years-old) & 62.2 (s.d.: 5.6) & 59.4 (s.d.: 5.5) & $<0.001$ \\
\hline Male sex (\%) & 140 (54.1\%) & $2663(46 \%)$ & 0.003 \\
\hline Proton pump inhibitor & $134(60 \%)$ & $874(15 \%)$ & $<0.001$ \\
\hline \multicolumn{4}{|l|}{ Cardiac disease } \\
\hline Valve prosthesis & $28(12.5 \%)$ & - & \multirow{4}{*}{$<0.001$} \\
\hline Atrial fibrillation & $140(62.5 \%)$ & $128(2.2 \%)$ & \\
\hline Prevention thromboembolism & $42(18.75 \%)$ & - & \\
\hline Others & $14(6.5 \%)$ & - & \\
\hline Ischemic stroke-heart & $67(30 \%)$ & $320(5.5 \%)$ & $<0.001$ \\
\hline \multicolumn{4}{|l|}{ Results of colonoscopy } \\
\hline Cancer & $1(4.8 \%)$ & 19 (5.2\%) & \multirow[t]{4}{*}{0.5} \\
\hline Advanced adenoma & $9(42.9 \%)$ & 165 (45.2\%) & \\
\hline Non-advanced adenoma & $4(19 \%)$ & $64(17.5 \%)$ & \\
\hline Normal & 7 (33.3\%) & $117(32.1 \%)$ & \\
\hline \multicolumn{4}{|l|}{ Location of lesions } \\
\hline Distal & 10 (71.5\%) & $180(72.6 \%)$ & \multirow[t]{2}{*}{0.5} \\
\hline Proximal & $4(28.5 \%)$ & $68(27.4 \%)$ & \\
\hline
\end{tabular}

Table 2. Comparison of FIT-positive rate between OACs non-user and user groups

\begin{tabular}{|l|c|c|c|c|c|}
\hline & $\begin{array}{c}\text { Indivi- } \\
\text { duals }\end{array}$ & $\begin{array}{c}+ \text { FIT, } \\
\text { no. (\%) }\end{array}$ & OR $^{\mathbf{a}}$ & $\mathbf{9 5 \% ~ C l}$ & $\boldsymbol{P}_{\text {-value }}$ \\
\hline Non-users group & 5821 & $365(6.2)$ & 1 (Ref.) & & \\
\hline Users group & 224 & $21(9.3)$ & 1.3 & $0.8-2.1$ & 0.3 \\
\hline OAC & 164 & $13(7.9)$ & 1.15 & $0.6-2.1$ & 0.6 \\
OAC +others & 60 & $8(13.3)$ & 1.8 & $0.8-3.9$ & 0.2 \\
\hline
\end{tabular}

Abbreviations: $\mathrm{Cl}=$ confidence interval; $\mathrm{FIT}=$ faecal immunochemical test; $\mathrm{OAC}=$ oral anticoagulant; $\mathrm{OR}=$ odds ratio; Others $=$ aspirin $\leqslant 300 \mathrm{mg} \mathrm{day}^{-1}$ or clopidogrel.

${ }^{a} \mathrm{OR}$, comparing users with non-users, adjusted for age and sex.

${ }^{b}$ Compared with non-users.

thromboembolism, but at the same time the therapy increases the risk of bleeding.

In our study, the $\mathrm{OAC}$ alone or in combination with antiplatelet drugs showed increased FIT positivity without increasing the false positivity rate. The rate of positive for control, OAC and the combination were $6.2 \%, 7.9 \%$ and $13.3 \%$, respectively. There were no statistically significant differences in the PPV for AN in comparing with non-users. Only three studies (Levi et al, 2009; Sawhney et al, 2010; Mandelli et al, 2011) have analysed the effect of OAC on the FIT performance. A study (Levi et al, 2009) includes 16 individuals taking warfarin, nevertheless, concluded that anticoagulants were associated increased sensitivity with no change in specificity for NA. Another study (Mandelli et al, 2011) examines 53 patients taking OAC with positive FIT and compared with 106 controls (positive FIT without OAC). Advanced neoplasia was detected in $28.3 \%$ of cases and $34.9 \%$ of controls without statistically significant difference. The third study (Sawhney et al, 2010) concluded that OAC reduces the PPV for AN compared with controls ( $20 \%$ in OAC vs $30 \%$ in controls). However, this
Table 3. AN found in each group

\begin{tabular}{|c|c|c|c|c|c|}
\hline & $\begin{array}{l}\text { Indivi- } \\
\text { duals }\end{array}$ & $\begin{array}{c}\text { AN, } \\
\text { no. (\%) }\end{array}$ & $\mathrm{OR}^{\mathrm{a}}$ & $95 \% \mathrm{Cl}$ & $P$-value ${ }^{b}$ \\
\hline Non-users group & 5821 & $184(3.2)$ & 1 (Ref.) & & \\
\hline Users group & 224 & $10(4.5)$ & 1.1 & $0.5-2.1$ & 0.8 \\
\hline OAC & 164 & $4(2.4)$ & 0.6 & $0.2-1.7$ & 0.4 \\
\hline OAC + others & 60 & $6(10)$ & 2.3 & $0.9-5.9$ & 0.08 \\
\hline \multicolumn{6}{|c|}{$\begin{array}{l}\text { Abbreviations: } \mathrm{AN}=\text { advanced neoplasm; } \mathrm{Cl}=\text { confidence interval; } \mathrm{FIT}=\text { faecal immuno- } \\
\text { chemical test; } \mathrm{OAC}=\text { oral anticoagulant; } \mathrm{OR}=0 \mathrm{odds} \text { ratio; Others = aspirin } \leqslant 300 \mathrm{mg}^{-1} \text { day }^{-1} \\
\text { or clopidogrel. } \\
\text { a } \mathrm{OR} \text {, comparing users with non-users, adjusted for age and sex. } \\
{ }^{\mathrm{b}} \text { Compared with non-users. }\end{array}$} \\
\hline
\end{tabular}

Table 4. Positive predictive value of faecal immunochemical test for AN according to group and user group

\begin{tabular}{|l|c|c|c|c|c|}
\hline & $\begin{array}{c}\text { FIT } \\
\text { positive }\end{array}$ & $\begin{array}{c}\text { PPV for } \\
\text { AN } \\
\text { no. (\%) }\end{array}$ & OR & $\mathbf{9 5 \% ~ C l ~}$ & P-value $^{\text {a }}$ \\
\hline Non-users & 365 & $184(50.4)$ & 1 (Ref.) & & \\
\hline Users group & 21 & $10(47.6)$ & 0.7 & $0.3-1.8$ & 0.5 \\
\hline OAC & 13 & $4(30.8)$ & 0.4 & $0.1-1.3$ & 0.14 \\
OAC + others & 8 & $6(75)$ & 2.0 & $0.4-10.8$ & 0.4 \\
\hline
\end{tabular}

Abbreviations: $\mathrm{AN}=$ advanced neoplasia; $\mathrm{Cl}=$ confidence interval; $\mathrm{OAC}=$ oral anticoagulants; $\mathrm{OR}=$ odds ratio; Others $=$ aspirin $\leqslant 300 \mathrm{mg} \mathrm{day}^{-1}$ or clopidogrel; $\mathrm{PPV}=$ positive predictive value.

${ }^{\text {a }}$ Compared with non-users and adjusted for age and sex.

study has some differences with our research, the number of patients taking anticoagulants was lower (85 individuals), the test used was the haemoccult II and patients were not a screening program. In the latter study, the percentage of patients with CRC and $\mathrm{AN}$ was low, $3.1 \%$ and $24 \%$, respectively, probably due to the test performed. In our study, the proportion of CRC and AN in patients with positive FIT was 5\% and 50\%, respectively. Our data suggest that combination therapy increases bleeding of $\mathrm{AN}$ facilitating their detection with FIT. Another advantage by not suspending the anticoagulant is that it can also help increase public participation in CRC screening since discontinuation has been linked to increased risk of stroke and other adverse cardiovascular events (Blacker et al, 2003).

This study has certain strengths. First, its database was that of a prospective clinical trial without selection bias, which should minimise confounders for the detection of AA and AN. Second, the number of cases analysed is higher than that reported to date (Levi et al, 2009; Sawhney et al, 2010; Mandeli et al, 2011). Third, the original trial was performed with FIT, unlike others which have used the guaiac faecal occult blood test (Sawhney et al, 2010). Finally, the study was performed in asymptomatic individuals, in contrast to other studies (Levi et al, 2009; Sawhney et al, 2010).

The study also has some limitations. First, colonoscopy was not performed on patients with a negative FIT, so we were not able to determine the influence OAC drugs may have had on the negative predictive value of FIT. Second, no information was collected on prothrombin time-international normalised ratio at the time of the FIT. Third, other factors such as history of gastrointestinal bleeding or presence of serious comorbid conditions (acute myocardial infraction, renal insufficiency and severe anaemia), can interfere results. Finally, the number of patients in the combined group (OAC more antiplatelets) with positive FIT and AN were low. 
In conclusion, we found that the anticoagulants alone or in combination with antiplatelet drugs did not reduce the PPV of FIT for AN. This suggests that OAC therapy should not be discontinued before stool collection for FIT.

\section{ACKNOWLEDGEMENTS}

This work was supported by grants from Asociación Española contra el Cáncer (Fundación Científica and Junta de Barcelona), the Instituto de Salud Carlos III (PI08/90717) and Agència de Gestió d'Ajuts Universitaris i de Recerca (2009SGR849). Centro de Investigación Biomédica en Red de Enfermedades Hepáticas y Digestivas (CIBERehd) is funded by Instituto de Salud Carlos III. In the Basque Country, the study received additional support with grants from Obra Social de Kutxa, Diputación Foral de Gipúzkoa (DFG 07/5), Departamento de Sanidad del Gobierno Vasco, EITBMaratoia (BIO 07/CA/19) y the Acción Transversal contra el Cáncer del CIBERehd (2008). In Galicia, this work was supported by Dirección Xeral de Innovación e Xestión da Saúde Pública, Conselleria de Sanidade, Xunta de Galicia. OC-Micro instruments and FITs were kindly provided by Eiken Chemical Co., Ltd, Japan, and its Spanish representatives, Palex Medical and Biogen; none of them were involved in the design of study or in the analysis or interpretation of results.

\section{CONFLICT OF INTEREST}

The authors declare no conflict of interest.

\section{AUTHOR CONTRIBUTIONS}

LB, AL, EQ and A Castells developed the study concept and design and drafted the manuscript. EQ, A Castells, JC, VH, JDM, TP-F, DS, MA, FC, XB, IP, RJ, FB, A Cosme and A Castells acquired the clinical data, designed and analysed the database and interpreted the data. LB and CS carried out the statistical analysis of data and contributed to the interpretation of data. All had the opportunity to revise the manuscript.

\section{REFERENCES}

Blacker DJ, Wijdicks EF, Mc Clellland RL (2003) Stroke risk in anticoagulated patients with atrial fibrillation undergoing endoscopy. Neurology $\mathbf{6 1}$ : 964-968.

Bujanda L, Lanas A, Quintero E, Castells A, Sarasqueta C, Cubiella J, Hernandez V, Morillas JD, Perez-Fernández T, Salas D, Andreu M,
Carballo F, Bessa X, Cosme A, Jover R. COLONPREV Study Investigators (2013) Effect of aspirin and antiplatelet drugs on the outcome of fecal immunochemical test. Mayo Clin Proc 88: 683-689.

Dossett LA, Riesel JN, Griffin MR, Cotton BA (2011) Prevalence and implications of preinjury warfarin use. Arch Surg 146: $565-570$.

Fraser CG, Allison JE, Halloran SP, Young GP; Expert Working Group on Fecal Immunochemical Tests for Hemoglobin; Colorectal Cancer Screening Committee; World Endoscopy Organization (2012) A proposal to standardize reporting units for fecal immunochemical tests for hemoglobin. J Natl Cancer Inst 104: 810-814.

Jover R, Herráiz M, Alarcón O, Brullet E, Bujanda L, Bustamante M, Campo R, Carreño R, Castells A, Cubiella J, García-Iglesias P, Hervás AJ, Menchén P, Ono A, Panadés A, Parra-Blanco A, Pellisé M, Ponce M, Quintero E, Reñé JM, Sánchez del Río A, Seoane A, Serradesanferm A, Soriano Izquierdo A, Vázquez Sequeiros E. Spanish Society of Gastroenterology; Spanish Society of Gastrointestinal Endoscopy Working Group (2012) Clinical practice guidelines: quality of colonoscopy in colorectal cancer screening. Endoscopy 44: 444-451.

Levi Z, Rozen P, Hazazi R, Vilkin A, Waked A, Maoz E, Birkenfeld S, Lieberman N, Klang S, Niv Y (2009) Sensitivity, but not specificity, of a quantitative immunochemical fecal occult blood test for neoplasia is slightly increased by the use of low-dose aspirin, NSAIDs and anticoagulants. Am J Gastroenterol 104: 933-938.

Levin B, Lieberman DA, McFarland B, Andrews KS, Brooks D, Bond J, Dash C, Giardiello FM, Glick S, Johnson D, Johnson CD, Levin TR, Pickhardt PJ, Rex DK, Smith RA, Thorson A, Winawer SJ; American Cancer Society Colorectal Cancer Advisory Group; US Multi-Society Task Force; American College of Radiology Colon Cancer Committee (2008) Screening and surveillance for the early detection of colorectal cancer and adenomatous polyps, 2008: a joint guideline from the American Cancer Society, the US Multi-Society Task Force on Colorectal Cancer, and the American College of Radiology. Gastroenterology 134: 1570-1595.

Mandelli G, Radaelli F, Paggi S, Terreni N, Gola G, Gramegna M, Bonaffini A, Terruzzi V (2011) Anticoagulant or aspirin treatment does not affect the positive predictive value of an immunological fecal occult blood test in patients undergoing colorectal cancer screening: results from a nested in a cohort case-control study. Eur J Gastroenterol Hepatol 23: 323-326.

Quintero E, Castells A, Bujanda L, Cubiella J, Salas D, Lanas Á, Andreu M, Carballo F, Morillas JD, Hernández C, Jover R, Montalvo I, Arenas J, Laredo E, Hernández V, Iglesias F, Cid E, Zubizarreta R, Sala T, Ponce M, Andrés M, Teruel G, Peris A, Roncales MP, Polo-Tomás M, Bessa X, Ferrer-Armengou O, Grau J, Serradesanferm A, Ono A, Cruzado J, Pérez-Riquelme F, Alonso-Abreu I, de la Vega-Prieto M, Reyes-Melian JM, Cacho G, Díaz-Tasende J, Herreros-de-Tejada A, Poves C, Santander C, González-Navarro A. COLONPREV Study Investigators (2012) Colonoscopy versus fecal immunochemical test in colorectal cancer screening. $N$ Engl J Med 366: 697-706.

Sawhney MS, McDougall H, Nelson DB, Bond JH (2010) Fecal occult blood test in patients on low-dose aspirin, warfarin, clopidogrel, or non-steroidal anti-inflammatory drugs. Dig Dis Sci 55: 1637-1642.

Supplementary Information accompanies this paper on British Journal of Cancer website (http://www.nature.com/bjc) 